\title{
Translocation stress is reflected in corticosterone metabolites in pheasant (Phasianus colchicus) droppings
}

\author{
Martina Volfová1, Rupert Palme², Zuzana Machovcová1, Eva Voslářová1, \\ Gabriela Lukešová ${ }^{1}$, Vladimír Večerek ${ }^{1}$
}

\begin{abstract}
${ }^{1}$ University of Veterinary Sciences Brno, Faculty of Veterinary Hygiene and Ecology, Department of Animal Protection and Welfare \& Veterinary Public Health, Brno, Czech Republic ${ }^{2}$ University of Veterinary Medicine Vienna, Department of Biomedical Sciences, Austria
\end{abstract}

Received October 20, 2021

Accepted November 23, 2021

\begin{abstract}
Translocation (including transportation and experiencing a new environment) represents a significant stressor for animals. The aim of this study was to assess changes in corticosterone metabolite (CM) levels related to translocation in common pheasants (Phasianus colchicus). Sixteen birds ( 8 males and 8 females) aged 17 weeks were crated and transported for $3.5 \mathrm{~h}$ (distance travelled $140 \mathrm{~km}$ ) to the target customer. Serial individual droppings were collected from 2 days prior until 3 days after transport. Concentrations of CMs in droppings were determined with a non-commercial cortisone enzyme immunoassay (EIA). Transport stress resulted in increased $\mathrm{CM}$ concentrations in the droppings in our study. The CM concentrations significantly increased within $2.5 \mathrm{~h}$ of transport $(P<0.01)$ compared to pre-transport levels $(747 \mathrm{ng} / \mathrm{g} \mathrm{vs} .187 \mathrm{ng} / \mathrm{g})$. After additional $3 \mathrm{~h}$, the $\mathrm{CM}$ concentrations fell back to the baseline levels $(207.7 \mathrm{ng} / \mathrm{g})$. In the new environment, the second peak (median: $1383 \mathrm{ng} / \mathrm{g}$ ) was determined with CM concentrations increasing $(P<0.01)$ compared to baseline levels. This increase was likely connected to the stress resulting from the new environment. The $\mathrm{CM}$ levels returned back to the baseline level $26 \mathrm{~h}$ after the start of transportation. No differences in concentrations of CM between sexes were found in our study. The utilized cortisone EIA proved suited to detect biologically meaningful alterations in adrenocortical activity of pheasants exposed to procedures related to their transport.
\end{abstract}

Phasianus colchicus, transport, adrenocortical activity, glucocorticoids, welfare

In recent years, increasing attention has been given to animal welfare issues on all types of farms (e.g. Večerek et al. 2020; Renčínová et al. 2021). While there are many definitions of welfare, the majority of authors agree that animal welfare is comprised of two elements - the physical health of the animals and their emotional state. Physical health includes the absence of disease and injury, adequate feeding, and physical and thermal comfort. The second element of welfare, the emotional state, includes both the absence of negative emotions and the presence of positive ones (Yates and Main 2005; Carenzi and Verga 2009; Manteca and Salas 2015). Poor welfare often results in stress. Stress, and in particular chronic stress, may have negative effects on the immune system, reproduction and behaviour (Morgan and Tromborg 2007).

Stressors of various kinds may be responsible for the activation of the hypothalamicpituitary-adrenal axis (HPA), thereby initiating the secretion of the corresponding hormones (Palme et al. 2005). The main secreted hormones produced by the adrenal cortex are glucocorticoids, namely cortisol and corticosterone, the latter being secreted on a predominant basis in birds (Möstl and Palme 2002; Palme et al. 2005). Monitoring endocrine markers is a well-known method for evaluating stress. Blood sampling has considerable limitations. In birds, capture and subsequent blood collection is extremely stressful and has a noticeable effect on the concentration of glucocorticoids

Address for correspondence:

MVDr. Martina Volfová, Ph.D.

Department of Animal Protection and Welfare \& Veterinary Public Health

Faculty of Veterinary Hygiene and Ecology

University of Veterinary Sciences Brno

Palackého tř. 1946/1, 61242 Brno, Czech Republic

Phone: +420734591865

E-mail: volfovam@vfu.cz

http://actavet.vfu.cz/ 
(Rettenbacher et al. 2004). Determination of hormone metabolites from droppings, however, minimises the effect of sample collection on hormone levels and enables frequent collection (Malikova et al. 2018). Non-invasive methods for monitoring adrenocortical activity, however, require validation for each new species under investigation (Dehnhard et al. 2003; Möstl et al. 2005; Touma and Palme 2005; Palme 2019).

Non-invasive evaluation of stress levels in birds has been conducted in a number of studies (Palme 2019). The relationship between levels of corticosterone in plasma and droppings in three bird species, specifically the chicken (Gallus domesticus), great cormorant (Phalacrocorax carbo) and northern goshawk (Accipiter gentilis) was assessed by an adrenocorticotropic hormone (ACTH) challenge test (Dehnhard et al. 2003). Further, a newly developed cortisone enzyme immunoassay (EIA) for measuring corticosterone metabolites with a 3,11-dione structure has been developed and physiologically and biologically validated for chicken (Gallus gallus) droppings (Rettenbacher et al. 2004; Rettenbacher and Palme 2009). With the same cortisone EIA, ACTH test related changes in concentrations of corticosterone metabolites (CMs) have also been observed in the droppings of other Galliformes, the Japanese quail (Coturnix japonica; Busso et al. 2013), the capercaillie (Tetrao urogallus; Thiel et al. 2005) and the black grouse (Tetrao tetrix; Baltic et al. 2005). In all three species the same cortisone EIA has proved well suited. No such non-invasive methods have been utilized so far in the common pheasant (Phasianus colchicus), another gallinaceous bird frequently kept in captivity worldwide. Studies monitoring stress in captive-reared pheasants in connection with various periods of handling (Chloupek et al. 2009) and transport (Voslarova et al. 2006; 2012) have relied on traditional analysis of glucocorticoids and other stress markers (lactate and glucose) in the blood plasma.

The aim of this study was to assess changes in CM levels in the droppings of the common pheasant (Phasianus colchicus) in connection with translocation. Transport has been proven to represent a significant stressor for animals (Mitchell and Kettlewell 2009), thus such a procedure can be used to biologically validate the said methods (Touma and Palme 2005; Palme 2019).

\section{Materials and Methods}

The monitoring was performed before and after transport at a pheasant rearing facility. Sixteen pheasants (eight of each sex) were selected at random for the purposes of the study and placed individually in cages for a period of two weeks before transport. However, all birds were in visual, vocal, and olfactory contact with each other for the entire research period. Each individual was also fitted with a different coloured ring on the leg for the purposes of differentiation of the birds. Food and water were provided ad libitum during the entire period. At the age of 17 weeks, pheasants were loaded into transport crates and transported for a period of $3.5 \mathrm{~h}$ over a distance of $140 \mathrm{~km}$ to the final customer. Samples of droppings were collected over a period of 2 days before (for the determination of baseline concentrations) and 3 days after transport. On the first day of observation, only 3 samples were taken, whereas the day before the transport and during three days after the transport, samples were taken much more frequently, depending on the spontaneous defecation of the birds. The samples were collected only during day time. The specific collection intervals are stated in Table 1.

Plastic trays were installed beneath the cages, from which droppings could be easily collected without stressing the birds. A total of 448 samples were collected (28 samples from each of the 16 birds) within an hour of defecation and placed in sealable plastic bags, before being labelled and frozen at $-20{ }^{\circ} \mathrm{C}$. Processing and analysis of the samples were performed at the University of Veterinary Medicine in Vienna, Austria. Briefly, samples were defrosted, individually homogenised and then weighed into test tubes at a weight of $0.5 \mathrm{~g}$. An amount of $5 \mathrm{ml}$ of $60 \%$ methanol was added to each sample (Palme et al. 2013). Following shaking (30 $\mathrm{min})$ and centrifugation $(3,750 \mathrm{~g}, 10 \mathrm{~min})$, concentrations of CMs were determined using a cortisone enzyme immunoassay (EIA) developed at the laboratory. Details of the EIA including cross-reactions are described by Rettenbacher et al. (2004). Values were expressed as ng CMs per g of droppings.

The concentrations of CMs in all sixteen animals were compared in the period from two days prior to the transport to three days after. First, the baseline level (ng/g), peak level (ng/g), x-fold increase of peak level above baseline concentrations, and duration of the peak and lag time in hours between time of transportation and peak response for each animal were computed. The baseline level was determined as the median of the concentrations measured for each pheasant before the stress impact. Second, the results were analysed using the 
Table 1. The collection intervals of droppings during the observation period.

\begin{tabular}{|c|c|c|c|c|}
\hline \multirow{11}{*}{ Pre-transport sampling } & Date & Samples order & Sampling time interval & $\begin{array}{c}\text { Hours before and after } \\
\text { start of transportation }\end{array}$ \\
\hline & \multirow{3}{*}{$08 / 28 / 2017$} & 1 & 09:10-10:05 & $-45 \mathrm{~h}$ \\
\hline & & 2 & $12: 17-12: 57$ & $-42 \mathrm{~h}$ \\
\hline & & 3 & $15: 30-16: 23$ & $-39 \mathrm{~h}$ \\
\hline & \multirow{6}{*}{$08 / 29 / 2017$} & 4 & 09:25-09:40 & $-20 \mathrm{~h}$ \\
\hline & & 5 & $12: 00-12: 45$ & $-18 \mathrm{~h}$ \\
\hline & & 6 & $13: 35-14: 15$ & $-17 \mathrm{~h}$ \\
\hline & & 7 & $14: 35-15: 30$ & $-16 \mathrm{~h}$ \\
\hline & & 8 & $15: 50-16: 25$ & $-15 \mathrm{~h}$ \\
\hline & & 9 & $16: 55-17: 30$ & $-14 \mathrm{~h}$ \\
\hline & $08 / 30 / 2017$ & 10 & 07:30-07:55 & Loading time \\
\hline \multirow{18}{*}{ Post-transport sampling } & \multirow{7}{*}{$08 / 30 / 2017$} & 11 & $12: 50-13: 55$ & $+1.5 \mathrm{~h}$ \\
\hline & & 12 & $14: 10-14: 45$ & $+2.5 \mathrm{~h}$ \\
\hline & & 13 & $14: 50-15: 35$ & $+3.5 \mathrm{~h}$ \\
\hline & & 14 & $16: 00-16: 35$ & $+4.5 \mathrm{~h}$ \\
\hline & & 15 & $17: 05-17: 35$ & $+5.5 \mathrm{~h}$ \\
\hline & & 16 & $18: 25-19: 00$ & $+6.5 \mathrm{~h}$ \\
\hline & & 17 & 19:30-20:00 & $+7.5 \mathrm{~h}$ \\
\hline & \multirow{9}{*}{$08 / 31 / 2017$} & 18 & $05: 40-06: 25$ & $+18 \mathrm{~h}$ \\
\hline & & 19 & $06: 50-07: 40$ & $+19 \mathrm{~h}$ \\
\hline & & 20 & 07:30-08:55 & $+20 \mathrm{~h}$ \\
\hline & & 21 & 09:00-10:30 & $+21 \mathrm{~h}$ \\
\hline & & 22 & $10: 15-10: 55$ & $+22 \mathrm{~h}$ \\
\hline & & 23 & $11: 20-11: 50$ & $+23 \mathrm{~h}$ \\
\hline & & 24 & $12: 10-12: 55$ & $+24 \mathrm{~h}$ \\
\hline & & 25 & $14: 20-15: 05$ & $+25 \mathrm{~h}$ \\
\hline & & 26 & $16: 50-17: 30$ & $+26 \mathrm{~h}$ \\
\hline & \multirow{2}{*}{ 09/01/2017 } & 27 & 08:00-09:00 & $+44 \mathrm{~h}$ \\
\hline & & 28 & $10: 00-10: 55$ & $+46 \mathrm{~h}$ \\
\hline
\end{tabular}

statistical package Unistat 5.6. (Unistat 198 Ltd., London, England). The normality of data was checked using Shapiro-Wilk test (Zar 1999). As the data was not normally distributed, nonparametric Friedman ANOVA test (Zar 1999) was used to compare the levels measured in all animals before and after the transport. To verify the possible influence of sex, the median levels of CMs were then calculated separately for males and females, and compared with one another with the use of the Kruskal-Wallis one-way analysis of variance. A $P$-value $<0.05$ was considered significant.

\section{Results}

As CM concentrations did not differ significantly $(P>0.05)$ between males and females, combined data for both sexes were used for further analysis. The CM concentrations measured in common pheasants before and during $46 \mathrm{~h}$ after translocation are presented in Fig. 1.

After transport, increased CM concentrations were seen in all 16 individuals. Baseline and peak levels, $x$-fold increase, the delay and duration of the peak determined during $7.5 \mathrm{~h}$ after the transport are presented in Table 2. 


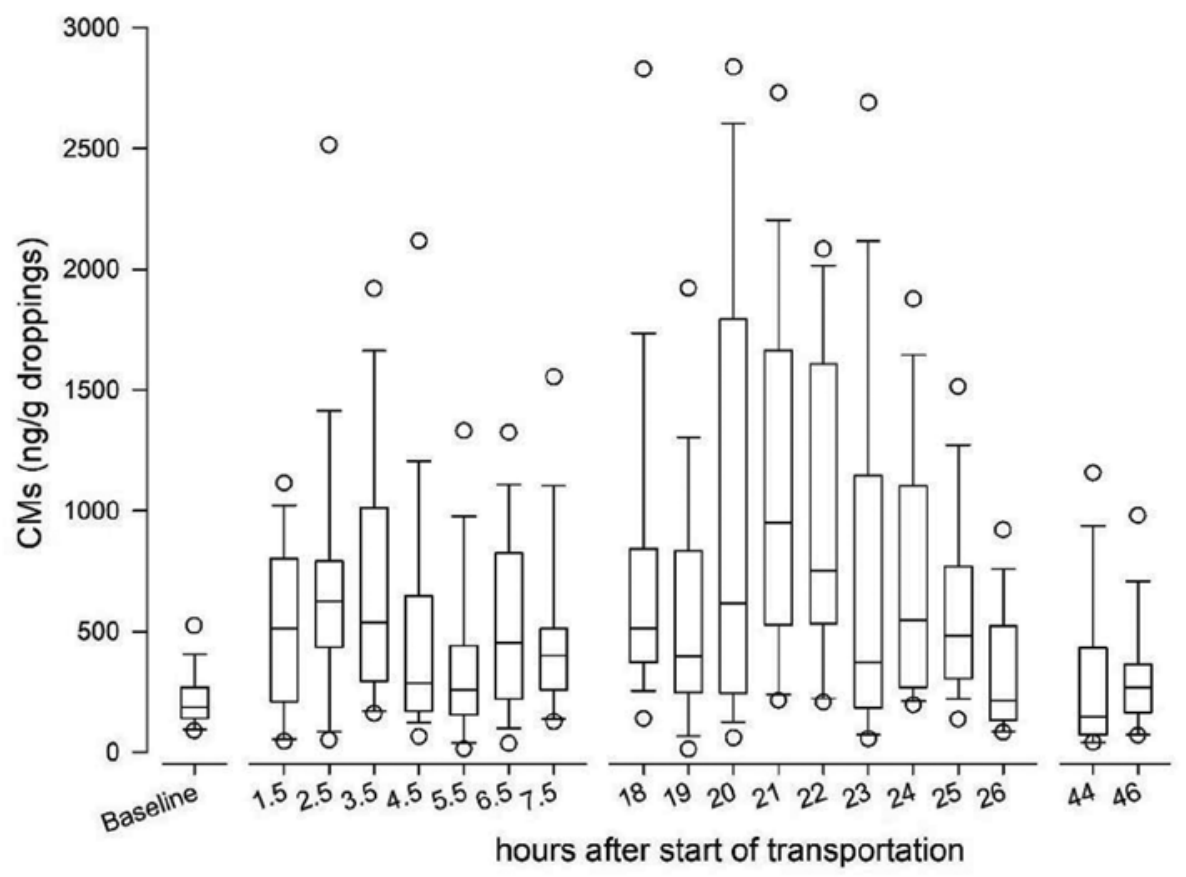

Fig. 1. Boxplot graph of concentrations of corticosterone metabolites (CMs) measured in common pheasants $(\mathrm{n}=16 ; 8$ of each sex) before and after translocation.

Table 2. Corticosterone metabolites in common pheasants in response to transport stress.

\begin{tabular}{|c|c|c|c|c|c|}
\hline & Baseline level $^{\mathrm{a}}$ & Peak level $^{\mathrm{b}}$ & $\mathrm{x}$-fold increase $\mathrm{e}^{\mathrm{c}}$ & Lag time ${ }^{\mathrm{d}}$ & Duration of the peak $(\mathrm{h})$ \\
\hline Female 1 & 89 & 276 & 3.1 & 1.5 & 2 \\
\hline Female 2 & 190 & 805 & 4.2 & 1.5 & 2 \\
\hline Female 3 & 525 & 2516 & 4.8 & 1.5 & 5 \\
\hline Female 4 & 168 & 783 & 4.7 & 1.5 & 3 \\
\hline Female 5 & 248 & 995 & 4.0 & 2.5 & 3 \\
\hline Female 6 & 184 & 766 & 4.2 & 2.5 & 3 \\
\hline Female 7 & 136 & 1132 & 8.3 & 2.5 & 3 \\
\hline Female 8 & 121 & 176 & 1.5 & 2.5 & 4 \\
\hline Male 1 & 209 & 728 & 3.5 & 1.5 & 3 \\
\hline Male 2 & 275 & 530 & 1.9 & 2.5 & 2 \\
\hline Male 3 & 354 & 1017 & 2.9 & 2.5 & 3 \\
\hline Male 4 & 307 & 512 & 1.7 & 2.5 & 3 \\
\hline Male 5 & 146 & 488 & 3.3 & 1.5 & 3 \\
\hline Male 6 & 206 & 714 & 3.5 & 1.5 & 1 \\
\hline Male 7 & 98 & 308 & 3.1 & 2.5 & 3 \\
\hline Male 8 & 154 & 1553 & 10.1 & 2.5 & 2 \\
\hline Median & 187 & 747 & 4.0 & 2.5 & 3 \\
\hline
\end{tabular}

${ }^{a}$ Baseline levels (ng/g droppings) determined for each individual as a median of all concentrations measured before the transport; ${ }^{b}$ Peak level (ng/g droppings) in response to transport; ${ }^{\mathrm{c}} \mathrm{X}$-fold increase of peak levels above baseline concentrations (peak/baseline level); ${ }^{\mathrm{d}}$ Lag time (h) between start of transportation and peak response 
The baseline CM levels of the 16 pheasants included in the study ranged from $89-525 \mathrm{ng} / \mathrm{g}$ droppings, the overall median baseline level was $187 \mathrm{ng} / \mathrm{g}$ droppings, while the median peak level was 747 (range: 176-2,516) ng/g droppings (Table 2). Nonparametric Friedman ANOVA test revealed significant differences $(P<0.001)$ between the median baseline level and the peak level (187 vs. $747 \mathrm{ng} / \mathrm{g}$ droppings). In all 16 animals the assay detected a change in response to transportation, as reflected by the 1.5-10.1-fold increase in the CM levels (Table 2).

The CM concentrations started to increase in the first interval collected after the start of transportation, with lag times to reach peak CM responses between 1.5 and $2.5 \mathrm{~h}$. Levels returned to the pre-stress levels within $3 \mathrm{~h}$ (median, range 1-5 hours) after the peak levels. Significant differences were found $(P<0.001)$ between the peak levels and the concentrations measured after the peak levels fell $(3 \mathrm{~h})$ to the baseline level (median 747 vs. $208 \mathrm{ng} / \mathrm{g}$ droppings). There were no significant differences $(P>0.05)$ between baseline levels measured before the transportation and the concentrations measured after $5.5 \mathrm{~h}$ (median $187 \mathrm{vs} 208 \mathrm{ng} / \mathrm{g}$ droppings).

In the new environment, a second increase in CM levels was found in the period between 18 to $26 \mathrm{~h}$ after translocation, as can be seen in Fig. 1. Details regarding the individual peaks of CM levels are presented in Table 3. Overall, the assay detected a 7-fold increase in $\mathrm{CM}$ concentrations. Subsequently, the CM levels returned back to baseline levels $26 \mathrm{~h}$ after start of transportation.

Table 3. Corticosterone metabolites in common pheasants in response to the new environment.

\begin{tabular}{|c|c|c|c|c|}
\hline & Baseline level $^{\mathrm{a}}$ & Peak level ${ }^{\mathrm{b}}$ & $\mathrm{x}$-fold increase $\mathrm{e}^{\mathrm{c}}$ & Duration of the peak $(\mathrm{h})$ \\
\hline Female 1 & 89 & 2732 & 30.6 & 7 \\
\hline Female 2 & 190 & 1132 & 6.0 & 7 \\
\hline Female 3 & 525 & 2829 & 5.4 & 3 \\
\hline Female 4 & 168 & 1172 & 7.0 & 7 \\
\hline Female 5 & 248 & 559 & 2.3 & 6 \\
\hline Female 6 & 184 & 1882 & 10.2 & 7 \\
\hline Female 7 & 136 & 644 & 4.7 & 9 \\
\hline Female 8 & 121 & 1334 & 11.0 & 6 \\
\hline Male 1 & 209 & 1402 & 6.7 & 2 \\
\hline Male 2 & 275 & 2837 & 10.3 & 4 \\
\hline Male 3 & 354 & 1980 & 5.6 & 7 \\
\hline Male 4 & 307 & 1363 & 4.4 & 6 \\
\hline Male 5 & 146 & 2083 & 14.2 & 4 \\
\hline Male 6 & 206 & 968 & 4.7 & 4 \\
\hline Male 7 & 98 & 1139 & 11.6 & 2 \\
\hline Male 8 & 154 & 2690 & 17.5 & 4 \\
\hline Median & 187 & 1383 & 7.4 & 6 \\
\hline
\end{tabular}

${ }^{a}$ Baseline levels (ng/g droppings) determined for each individual as a median of all concentrations measured before the transport; ${ }^{b}$ Peak level (ng/g droppings) in response to the new environment; ${ }^{\mathrm{c}} \mathrm{X}$-fold increase of peak levels above baseline concentrations (peak/baseline level)

\section{Discussion}

In this study we assessed changes in the CM levels in the droppings of the common pheasant in connection with translocation. The transport of pheasants from rearing facilities to the final customer is common practice in European countries (Draycott et al. 2005; Voslarova et al. 2012). Birds are transported over short and long distances at various age 
categories, and are confronted with a number of stressors during and after transportation, such as capture, placement in crates, loading, transport, and unloading into a new environment. Moreover, the welfare of the animals during transport itself is affected by a large number of other factors, such as temperature, humidity, density of occupation of the transport box and length of transport, as well as time of day and season of the year (Morgan and Tromborg 2007; Mitchell and Kettlewell 2009). The handling of the animal itself can be considerably stressful, as has been shown by a number of studies (Balcombe et al. 2004; Chloupek et al. 2009) measuring blood corticosterone concentrations. The organism's response to stress was expected to be also reflected in CM levels in the droppings. This has been confirmed in our study, in which the transport of common pheasants for around three hours resulted in CM levels higher than those before transport. While the median pre-transport CM level was $187 \mathrm{ng} / \mathrm{g}$, the median post-transport peak level increased to $728 \mathrm{ng} / \mathrm{g}$. Subsequently, the median CM level further increased to $1,383 \mathrm{ng} / \mathrm{g}$ droppings, likely due to the stress experienced in the new environment. The median increase of CMs in the first post-translocation peak was reflected by a 4-fold increase and the median increase of CMs in the second post-translocation peak was reflected by a 7-fold increase. An increase in CMs by more than three times has also been demonstrated in laying hens transported for one hour (Rettenbacher and Palme 2009).

The species-specific lag time in CM excretion depends on the type of metabolites, gut passage time, and the type of diet (Möstl and Palme 2002; Palme et al. 2005). The median lag time (which determines the delay in CM excretion from stress stimulus to peak response) in pheasants was $2.5 \mathrm{~h}$. Our findings correspond with another study reported for snow geese, where the CM levels in droppings started to increase about $1-2 \mathrm{~h}$ following injection of ACTH (Legagneux et al. 2011). Dehnhard et al. (2003) observed a significant increase in glucocorticoid metabolites in droppings at 2-6 h after ACTH administration to chickens (Gallus domesticus). Similarly, Rettenbacher and Palme (2009) found that transpo rting chicken significantly elevated CM concentrations during the first three hours. Baltic et al. (2005) detected peak concentrations after one or two hours. Rettenbacher et al. (2004) recorded peak levels of radiolabelled corticosterone in chicken droppings after $4.7 \mathrm{~h}$ in males and $3.4 \mathrm{~h}$ in females. The differences between lag time reported in different species and studies may be related to whether an EIA mainly picks up urinary or faecal metabolites in a bird species (droppings contain both parts). A quick peak will represent metabolites from the urine; a more delayed one those of the faecal portion (Retten bacher et al. 2004).

After the transport, the CM levels returned to the pre-stress levels within $3 \mathrm{~h}$ (median) after the peak levels in pheasants. However, a second peak likely related to the new environment was found 18 to $26 \mathrm{~h}$ after the start of translocation. Subsequently, CM levels returned back to baseline levels after further $6 \mathrm{~h}$. In chickens, the CM levels returned to baseline levels during 6-12 h after transport (Rettenbacher and Palme 2009). In their study, despite the chickens also being translocated to the new environment, the second peak was not seen. The results suggest that domestic chickens may adapt more easily to the new environment than pheasants.

Sex is commonly given as a factor affecting CM concentrations (Goymann 2005; Palme 2019). While Rettenbacher et al. (2004) found sex differences in domestic chicken, where higher CM levels were recorded in males, we found no sex differences in our study. However, some studies have, similar to our study, not observed any differences in CM levels: such as in the mourning dove (Zenaida macroura) or in the black grouse (Tetrao tetrix) (Washburn et al. 2003; Baltic et al. 2005). In our study, the lack of sex differences in CM levels may be well explained by the fact that the pheasants in our study were 17 weeks old and thus sexually immature (pheasants reach sexual maturity at the age of 32-40 weeks) and therefore their CM levels could not be affected by sex hormones yet. 
Since only 17 -week-old pheasants were monitored in our study, we could not evaluate differences in the pheasants' responses to transport-related stress based on their age. The results of previous studies indicated that individuals are more sensitive to the stress action of various factors, such as capture, placement in transport crates and transport itself, with increasing age (Yalçin et al. 2004). Similar results have also been published for common pheasants. Older (16 weeks) pheasants showed significantly higher corticosterone levels than younger ( 8 weeks) birds (Bedanova et al. 2018). Pheasants are transported not only for farming purposes but also to be released in the wild. Determining the most suitable age in relation to perceived stress and relevant transport planning may affect their subsequent survival.

The measurement of corticosterone metabolites using the cortisone EIA in the pheasants' droppings may be a valuable tool for further research exploring the effect of age on stress responses given its non-invasive character. This EIA has also been found suited for other Galliformes (Rettenbacher et al. 2004; Baltic et al. 2005; Thiel et al. 2005; Busso et al. 2013).

We conclude that the measurement targeting a group of metabolites with a 3,11-dione structure can be used as biological validation (first described by Rettenbacher et al. 2004). Our results indicate that the measurement of corticosterone metabolites using the cortisone EIA is suitable for the evaluation of adrenocortical activity in common pheasants. This non-invasive method can be used for the further assessment of stress in pheasants instead of traditional, invasive methods.

\section{Acknowledgements}

We would like to thank our dear colleague Dr. Pavel Forejtek, for making the research possible and for his help with sample collection. Also we would like to thank Edith Klobetz Rassam and Dr. Monika Šebánková for technical assistance with the EIA analysis. This study was supported by the Internal Creative Agency of the University of Veterinary Sciences Brno (Project No. FVHE/Vecerek/ITA2020).

\section{References}

Balcombe JP, Barnard ND, Sandusky C 2004: Laboratory routines cause animal stress. J Am Assoc Lab Anim Sci 43: 42-51

Baltic M, Jenni-Eiermann S, Arlettaz R, Palme R 2005: A noninvasive technique to evaluate human-generated stress in the black grouse. Ann NY Acad Sci 1046: 81-95

Bedanova I, Pistekova V, Forejtek P, Chloupek J, Voslarova E, Plhalova L, Vecerek V 2018: Short-time effect of stress associated with transport of juvenile pheasants (Phasianus colchicus) as affected by age. Berl Münch Tierärztl Wschr 131: 25-30

Busso J, Dominchin MF, Marin RH, Palme R 2013: Cloacal gland, endocrine testicular, and adrenocortical photoresponsiveness in male Japanese quail exposed to short days. Dom Anim Endocrinol 44: 151-156

Carenzi C, Verga M 2009: Animal welfare: review of the scientific concept and definition. Ital J Anim Sci 8: 21-30

Chloupek P, Voslarova E, Suchy Jr. P, Bedanova I, Pistekova V, Vitula F, Chkoupek J, Vecerek V 2009: Influence of pre-sampling handling duration on selected biochemical indices in the common pheasant (Phasianus colchicus). Acta Vet Brno 78: 23-28

Dehnhard M, Schreer A, Krone O, Jewgenow K, Krause M, Grossmann R 2003: Measurement of plasma corticosterone and fecal glucocorticoid metabolites in the chicken (Gallus domesticus), the great cormorant (Phalacrocorax carbo), and the goshawk (Accipiter gentilis). Gen Comp Endocrinol 131: 111-120

Draycott RAH, Woodburn MIA, Carroll JP, Sage RB 2005: Effects of spring supplementary feeding on population density and breeding success of released pheasants Phasianus colchicus in Britain. Wildlife Biol 11: 117-182

Goymann W 2005: Noninvasive monitoring of hormones in bird droppings: Physiological validation, sampling, extraction, sex differences, and the influence of diet on hormone metabolite levels. Ann NY Acad Sci 1046: $35-53$

Legagneux P, Gauthier G, Chastel O, Picard G, Bêty J 2011: Do glucocorticoids in droppings reflect baseline level in birds captured in the wild? A case study in snow geese. Gen Comp Endocrinol 172: 440-445

Malikova M, Voslarova E, Vecerek V 2018: Non-invasive faecal monitoring of stress in captive and free-ranging wild animals. Berl Münch Tierärztl Wschr 131: 150-158

Manteca X, Salas M 2015: Concept of animal welfare. ZAWEC 1: 1-2

Mitchell MA, Kettlewell PJ 2009: Welfare of poultry during transport - a review. Proceedings of the $8^{\text {th }}$ European Symposium on Poultry Welfare, Italy 
Morgan KN, Tromborg CHT 2007: Sources of stress in captivity. Appl Anim Behav Sci 102: 262-302

Möstl E, Palme R 2002: Hormones as indicators of stress. Domest Anim Endocrinol 23: 67-74

Möstl E, Rettenbacher S, Palme R 2005: Measurement of corticosterone metabolites in birds'droppings: An analytical approach. Ann NY Acad Sci 1046: 17-34

Palme R 2019: Non-invasive measurement of glucocorticoids: Advances and problems. Physiol Behav 199: 229-243

Palme R, Rettenbacher S, Touma C, El-Bahr SM, Möstl E 2005: Stress hormones in mammals and birds: Comparative aspects regarding metabolism, excretion, and noninvasive measurement in fecal samples. Ann NY Acad Sci 1040: 162-171

Palme R, Touma C, Arias N, Dominchin MF, Lepschy M 2013: Steroid extraction: Get the best out of faecal samples. Wiener Tierärztl Mschrift - Vet Med Austria 100: 238-246

Renčínová V, Voslářová E, Bedáňová I, Večerek V 2021: Pest flies on dairy farms affect behaviour and welfare of dairy cows during summer season. Acta Vet Brno 90: 255-262

Rettenbacher S, Möstl E, Hackl R, Ghareeb K, Palme R 2004: Measurement of corticosterone metabolites in chicken droppings. Br Poult Sci 45: 704-711

Rettenbacher S, Palme R 2009: Biological validation of a non-invasive method for stress assessment in chickens. Berl Münch Tierärztl Wschr 122: 8-12

Thiel D, Jenni-Eiermann S, Palme R 2005: Measuring corticosterone metabolites in droppings of capercaillies (Tetrao urogallus). Ann NY Acad Sci 1046: 96-108

Touma C, Palme R 2005: Measuring fecal glucocorticoid metabolites in mammals and birds: the importance of validation. Ann N Y Acad Sci 1046: 54-74

Večerek V, Voslářová E, Semerád Z 2020: Patho-anatomic findings in finisher pigs, sows and piglets detected during veterinary slaughterhouse inspection. Acta Vet Brno 89: 341-347

Voslarova E, Bedanova I, Chloupek P, Pistekova V, Chloupek J, Vecerek V 2012: Changes in selected biochemical indices in common pheasants in response to their transport. Folia Vet 56: 58-59

Voslarova E, Bedanova I, Vecerek V, Pistekova V, Chloupek P, Suchy P 2006: Changes in haematological profile of common pheasant (Phasianus colchicus) induced by transit to pheasantry. Dtsch Tierärztl Wochenschr 113: $361-400$

Washburn BE, Millspaugh JJ, Schulz JH, Jones SB, Mong T 2003: Using fecal glucocorticoids for stress assessment in mourning doves. Condor 105: 696-706

Yates JW, Main DCJ 2005: Assessment of positive welfare: A review. Vet J 175: 293-300

Yalçin S, Özkan S, Oktay G, Cabuk M, Erbayraktar Z, Bilgili SF 2004: Age-related effects of catching, crating, and transportation at different seasons on core body temperature and physiological blood parameters in broilers. J Appl Poult Res 13: 549-560

Zar JH 1999: Biostatistical Analysis. $4^{\text {th }}$ edn. Prentice-Hall, Inc., New Jersey, 663 p. 